\title{
Singing with a Distinctive Voice: Comparative Musical Analysis and the Central Australian Musical Style in the Kimberley
}

\author{
Sally Treloyn
}

\section{Introduction}

The history of ethnomusicological study of Australian Aboriginal music is rooted in European schools of musicological and analytical training. Early Australian ethnomusicologists such as Trevor Jones, Alice Moyle, and Catherine Ellis all incorporated analysis of musical form in research and scholarship on Australian Aboriginal song, setting a path for following generations who have included substantial musical analysis and transcription in their studies of Australian Aboriginal music (see Toner 2007). Musical analysis has subsequently substantially informed ethnomusicological inquiries into Aboriginal music in various parts of Central Australia (Catherine Ellis, Linda Barwick, Richard Moyle, Guy Tunstill, Myfany Turpin, Stephen Wild); the Western Desert (Anthony McCardell (Pritam), Richard Moyle); the Kimberley (Ray Keogh, Treloyn); the Daly-Fitzmaurice region (Allan Marett, Barwick); western Arnhem Land (Barwick, Reuben Brown); Tiwi Islands (Genevieve Campbell); and central, northeast, and eastern Arnhem Land (Guy Anderson, Steven Knopoff, Peter Toner, Jill Stubington, Wild), 
as well as various parts of Tasmania and southeastern Australia (Alice Moyle, Margaret Gummow). As Stephen Wild pointed out in 'Ethnomusicology Down Under: A Distinctive Voice in the Antipodes?' (2006), after training under Alan Merriam within the cultural anthropological school dominant in the United States of America in the 1960s, even he undertook processes of transcription and analysis to inform his understanding of Central Australian music and that of Arnhem Land (2006: 348). Having observed these analytical roots, Wild continues that 'Australian ethnomusicology has not fulfilled its promise as a comparative discipline, at least in the study of Aboriginal music' (ibid.: 350). 'Where did the comparison go?', he asks. 'Are we afraid of grand theoretical schemes? Does all our research have to be particularistic, limited in scope, focussed on the minutiae?' (ibid.: 349-50).

The answer to Wild's questions may indeed be 'yes'. Patrick Savage and Steve Brown (2013: 17-18) provide three reasons for the decline of comparative method in the discipline of ethnomusicology:

- Complexity. The task of comprehending multiple musical systems, and of comparing multiple, diverse systems, with common criteria and categories, is difficult.

- Politics. The historical association between comparative methodologies and the political/ideological context of racism, theories of Social Darwinism, and monogenesis dominant in the nineteenth and twentieth century.

- Sound versus meaning. The historical tendency of comparative musicologists to privilege acoustic features of music and dismiss context and social meaning.

In the case of analyses of Australian Aboriginal music, these three factors are intertwined. Barwick noted in 1989 with regard to the role that description of musical change might play in the theorisation of Aboriginal knowledge systems: 'because of the complexity of the music, no ethnomusicologist has yet arrived at such a description, despite the many years of analytical work undertaken by ethnomusicologists in a number of different geographical areas' (Barwick 1989: 12). Due to variability within and between musical systems, 'analysis of Aboriginal song (particularly analysis that seeks to understand the relationships between text and rhythm, and melody and text/rhythm) inevitably becomes a complicated technical feat' (Treloyn 2016). 
With regard to politics, several ethnomusicologists have reflected on the implications of undertaking notation and analysis of Aboriginal music in light of the complex colonial intercultural histories of Australia (see, for example, Marett, Warrigal, and Daly 1991; Knopoff 2003; Mackinlay 2012): notation and analysis risk 'eclips[ing] embodied processes of transmission, codification and interpretation' (Magowan 2007: 13), and becoming 'vehicles of sustained oppression, a tool of colonization' (Mackinlay 2012: 6). While he does not state precise reasons, in his 2006 article Wild pointed out that he 'did not dare' publish his extensive notations of Central Australian music early in his career (Wild 2006: 348). In light of the risks, we may indeed be afraid of comparative analysis, let alone 'grand theoretical schemes'.

That said, analysis has continued, and strengths-based approaches to the artistry and expertise of Aboriginal musicians and song traditions have wedded analysis and political consciousness. Marett, Warrigal, and Daly (1991) summed this up:

In the political context of Australia, with its history of neglecting and devaluing Aboriginal culture, those of us who are trained in ways that permit us to gain some appreciation of its complexity and subtlety may, with the agreement of the owners of the dances and songs, have a role in presenting our perceptions to the wider community. At the same time we need to work at devising strategies to avoid subsuming Aboriginal performers' realities to our systems of knowledge, and this involves our continuing to refine our awareness of the implications that our processes of documentation and analysis hold for the politics of representation. (Marett, Warrigal, and Daly 1991: 44)

In this approach, the complexity of Aboriginal Australian musical traditions contributes to a politically conscious analytical practice. Australian Aboriginal music 'resists the universalising aims of analysis' (Barwick 1989: 14) through practices such as irregularity and variability (Barwick 1989), parataxis, and minimal contrast (Barwick 2005a, 2005b; Treloyn 2007; Turpin, R. Moyle, and Bonney this volume).

With regard to musical analysis and social meaning, Savage and Brown recommend a comparative musicology that also examines musical behaviour and meaning; a blending of the analysis of acoustic and nonacoustic aspects of musical systems and cultures. The analytical tradition that has emerged in Australia, complex and particularistic, has been conducted with few exceptions in hand with or with the aim of better 
understanding sociocultural processes (see, for example, in this volume, Brown; Toner; and Turpin, R. Moyle, and Bonney). In traditions where musical variability is a marker of social action, fine-grained analysis of multiple songs within repertories, and multiple performances of songs, does not dismiss context and social meaning, but rather enables us to glimpse something of the social power of localised creative practices and to support community aspirations to sustain them.

This chapter responds to Wild's question 'Where did the comparison go?' with a demonstration of musical analysis of Aboriginal song that is at once comparative and focused on minutiae, and concerned with sociocultural meaning within performer-societies as well as in politically conscious cross-cultural research processes.

\section{Central Australian and Northern musical styles in the Kimberley}

In her taxonomy of music in northern Australia $(1966,1974)$, Alice Moyle identified a 'Central Australian musical region': a large geographically, linguistically, and culturally diverse region that corresponds broadly with the central Pama-Nyungan linguistic area (Turpin, pers. comm., July 2015; Bowern and Koch 2004). Several features are common to the song genres in this region, including (but not limited to) (see A. Moyle 1974; Keogh 1990; Barwick 2011):

- the relatively short duration of song items (approximately one minute);

- the use of relatively short song texts (or verses) that are repeated cyclically;

- isorhythmic and cyclical setting of song texts;

- cyclical melodic patterns;

- text/rhythm patterns that are non-coterminous with (i.e. independent of) melodic patterns; and

- regular beating accompaniments that are uniform within song items.

Previous studies have begun to document the extent to which public song genres in regions to the north of the Central Australian musical region (in the Kimberley) also exhibit these musical features (see A. Moyle 1977; Keogh 1990). In these categorisations, public, group-performed, dance-song genres indigenous to the Kimberley have been designated 
as examples of the Central Australian style. The resultant distribution suggests the Central Australian musical style extends beyond the PamaNyungan line into all four non-Pama-Nyungan language families of the Kimberley through genres such as (see Figure 1):

- ilma composed and performed by Bardi, and nurlu composed and performed by Nyikina (Nyulnyulan language family);

- junba composed and performed by Bunuba and Gooniyandi (Bunuban language family);

- junbalbalga and subgenres jadmi and jerregorl/galinda composed and performed by Ngarinyin, Wunambal, Worrorra, and related groups (Worrorran language family); and

- junbalbalga composed and performed by Gija, Miriwoong, and other groups (Jarrakan language family).

Insofar as junbalbalga musical forms have also been found in song genres indigenous to the Daly region-in malgarrin, which originated in the 1930s (Furlan 2008: 153), and djanba, which originated in the 1950s in Port Keats (Wadeye) based on junbalbalga (Barwick 2011; Treloyn 2014) - the Central Australian musical style is influential in the musical geography of group-performed songs in much of northwest Australia. It appears that the Central Australian musical style permeated much of the centre and northwest of the continent, from the south to the northern coast, evident to varying degrees in the genres of both PamaNyungan and non-Pama-Nyungan language families, from at least the 1930s if not earlier.

Looking more closely at the musical styles of the north, however, we see an equally pervasive musical migration moving from the north to the southwest. This 'Northern Australian style'—exhibited by manikay indigenous to northeast Arnhem Land (see Toner this volume), to kunborrk indigenous to western Arnhem Land (see Brown this volume), to wangga and lirrga indigenous to the Daly-Fitzmaurice region-has the following characteristics (amongst others):

- use of the didjeridu;

- relatively long duration of song items;

- relatively long song texts that are sectional and stanza-like (not strictly cyclical); and

- strophic, coterminous relationship between text/rhythm and melody. 


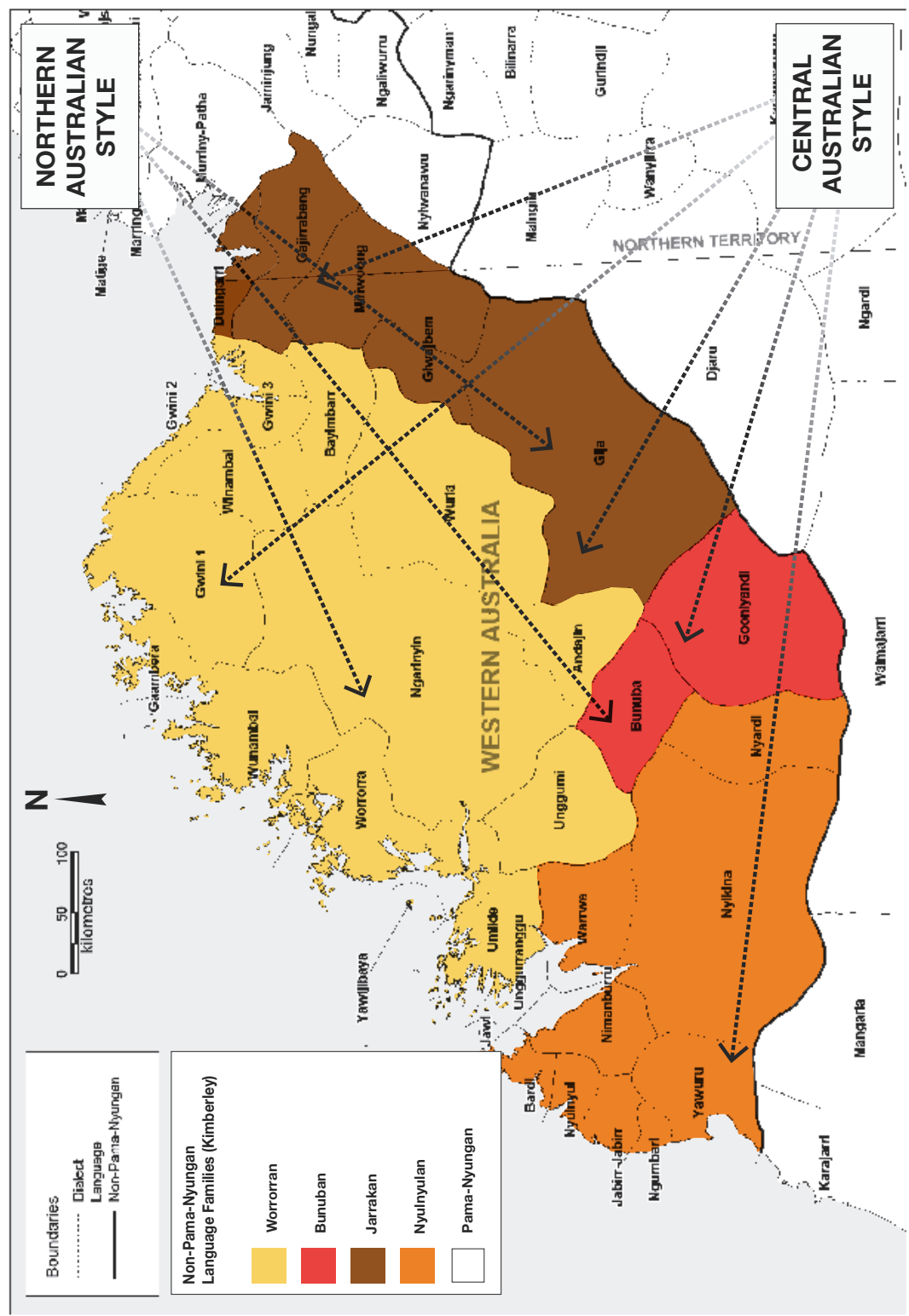

Figure 1. The spread of the Central Australian and Northern Australian musical styles in the Kimberley

Source: This map was collated by Mark Harvey (University of Newcastle) on the basis of contributions from many field researchers. Shading and annotations by Treloyn 
By at least the 1940s, wangga and lirrga migrated into the Kimberley (Marett 2005) with the movement of singers as stock workers, ceremony, and trade networks. Today wangga is incorporated into ceremony for initiation, and is almost ubiquitous in public festivals and celebrations in the Kimberley from the northeast to the southwest.

As indicated by Figure 1, a picture emerges of two intersecting distributions of musical style, one reaching from the north and the other from the south overlapping in the Kimberley. ${ }^{1}$

Understanding the distribution and spread of musical styles through the central region of Australia and the north sets a frame for more granular analytical studies, as well as studies of the trade systems, adjustments, and cultural patterns of distinct but related groups. Alberto Furlan, for example, shows how the new song styles that emerged in Port Keats (Wadeye) from the 1930s (malgarrin) to the present (djanba in the 1950s, and popular music in the 1980s) symbolise transitivity (Stanner 1966), but were also instrumental in (not just symbolic of) social process (Furlan 2008, see also Marett 2005). Barwick shows how the creators of djanba drew on the distinct musical style of Kimberley junba/balga within the familiar musical framework of the lirrga (and wangga) traditions to establish a new tripartite ceremonial complex and enhance social cohesion in the new social world of the Port Keats mission community in the 1950 s (Barwick 2011).

Such studies emphasise the importance of looking comparatively and regionally, but also considering the minutiae of what happens musically and socially at the geographic and cultural boundaries of musical regions - a task flagged by Alice Moyle (1966). The diverse musical scene of the Kimberley, where Central Australian and Northern musical styles meet, is conceivably a result of centuries of movement of day-to-day and sacred objects and knowledges between Kimberley and Desert groups on the one hand, and a burst of trade between the Kimberley and Daly in the twentieth century encouraged by social movement on stock routes and new economies on the other. What is happening socially, culturally, and politically where Central Australian and Northern styles meet in the Kimberley? How are the musical migrations we observe and instances

1 Preliminary analysis suggests that solo genres indigenous to the west Pilbara, such as thabi, display elements of both the Central and Northern musical styles (see Treloyn, Dowding, and Jebb 2015), providing a site of variegation for future analysis. 
of conscious variegation instruments for social change? The following section of this chapter focuses in on the minutiae of musical processes in the Kimberley to approach these questions, looking first to departures from the Central Australian style in Kimberley genres, and then at the contexts in which these departures are performed.

\section{Departures from the Central Australian style in the Kimberley: Nurlu and junba}

In the Central Australian musical style, a relatively short text (commonly referred to as a 'text cycle') is employed as the core lyrical content of each song performance. ${ }^{2}$ The repetition of this text cycle 'throughout the duration of each song item of the same sequence of songwords' is a feature of song through Central Australia and the Western Desert (A. Moyle 1977; see also Barwick 2011).

There is a long history of analysis of Central Australian musical systems that examines the rhythmic and melodic performance of text cycles. In songs in the Central Australian style, melodic and text/rhythm cycles are independent (see Ellis 1985; Barwick 1989) and non-coterminous (Barwick 2011):

- songs may begin on a word (or part of word) other than the first word of the text cycle;

- songs may end on a word (or part of word) other than the last word of the text cycle;

- boundaries of the text cycle do not necessarily coincide with boundaries of the melodic structure;

- subsequent performances of the same song may begin and end on different words in the text cycle.

By contrast, in the Northern Australian style, song texts exhibit noncyclical structures. Manikay in Arnhem Land, for example, often features a through-composed, tripartite structure (Knopoff 1992). Wangga, lirrga, and kun-borrk songs may contain repeated stanzas, but these are typically separated by instrumental sections (for example, see Brown in this volume). While djanba is modelled on junbalbalga from

2 Note that Turpin, R. Moyle, and Bonney (this volume) refer to this unit as a 'verse'. 
the Kimberley, it is characterised by repeated stanzas that may appear as cyclical; deviation from isorhythm; the use of instrumental sections; and a structure that is best described as strophic (Barwick 2011). What is common to these northern genres is a text unit that is coterminous with the melodic structure (ibid.). That is, major structural boundaries in the text cycle (such as the beginning and the end) coincide with major structural boundaries in the melodic cycle (such as the commencement of a sung section, and the end of a sung section).

The cyclical and isorhythmic performance of text cycles in Kimberley public group-song genres such as junbalbalga and nurlu, together with isorhythmic settings, has contributed to their classification as Central Australian in style (see A. Moyle 1977; Keogh 1990; Treloyn 2006). When we look more closely at performances of these genres, however, it is clear that they also exhibit some distinctive Northern features.

In the first detailed examination of Kimberley text cycles, Ray Keogh identified a practice of 'breaking' text cycles in the Nyikina nurlu repertory known as Bulu, composed by George Dyunggayan (1990: 207). While he does not provide examples, Keogh notes that in one third of the performances of Bulu that he analysed, a section of the text cycle ranging in duration from half of one beat (one syllable) to two beats is omitted when the singer takes a breath. While these short 'breaks' may be attributed to the nature of the performances in his sample, ${ }^{3}$ Keogh notes that in some performances the singer breaks the text cycle in a clearly conscious and deliberate way. In these cases, when the singer takes a breath he jumps to 'the beginning of one of the text lines within the cycle and continue[s] ... to sing that line in his head while taking the breath' (Keogh 1990: 206-7). Keogh's transcription of a performance of verse $1^{4}$ of the Bulu repertory illustrates this practice (see Figure 2). Verse 1

3 While it is customary for nurlu to be performed by a group of singers and accompany dance, Keogh's sample comprised solo performances and did not accompany dance (Keogh 1990: 16-18). In a group performance, with multiple voices, other singers may carry the cycle while the lead singer breathes. Additionally, in performances that are sung by a group and accompanied by dance, there is a necessity that the text/rhythmic cycle be maintained to ensure that the dancers and singers stay in unison. In solo, unaccompanied performances, there are no such requirements. Marett has similarly found that there is a reduced need for strict unisonic performance in the performance of wangga songs when songs are not accompanied by dance and are removed from their ceremonial context. He finds that song texts regularly vary in the Ma-yawa and Bunggridj-Bunggridj wangga repertories that were rarely, if ever, performed in ceremony: 'text phrases may be added or omitted, the order in which text phrases appear may change, and word order ... may be reworked' (Marett 2005: 200).

4 In this case a 'verse' is comparable to the term 'small song' employed by Turpin, R. Moyle, and Bonney in this volume, comprising multiple song items each using the same text cycle. 
has the text cycle wanydyalmirri yinganydyina mindi yarrabanydyina (ibid.: 92), where wanydyalmirri yinganydyina is labelled text-line A and mindi yarrabanydyina is labelled text-line $\mathrm{B}$. A complete iteration of the text cycle is provided in the second stave in Figure 2.

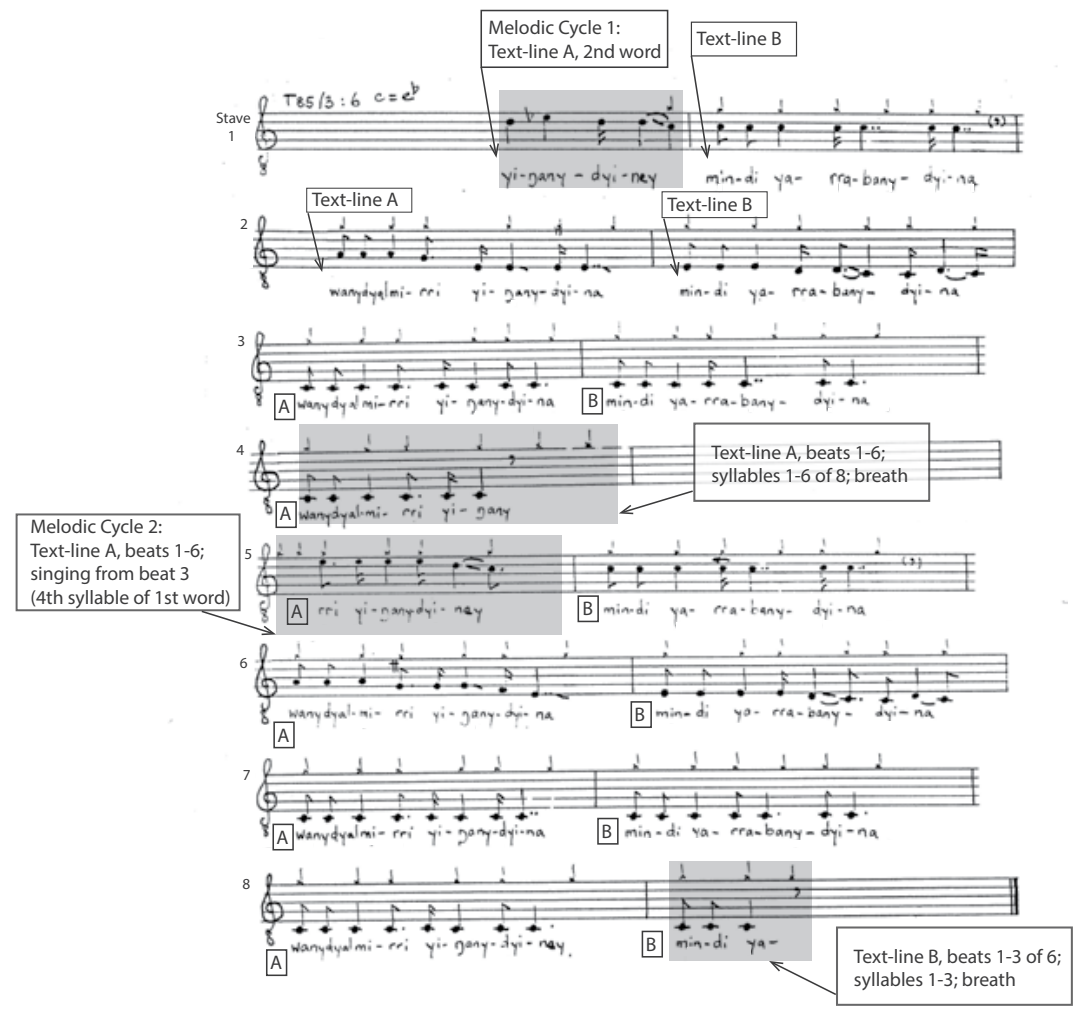

Figure 2. Bulu nurlu (composed by George Dyunggayan), 'verse 1, song item i'

Source: Transcription by Keogh (1990: 215-18); annotation by Treloyn

The text cycle, with the undoubled form $A B$, is performed with an isorhythmic setting that has a duration of 12 clapstick beats. As is common in the Central Australian style, the song begins partway through a text line, in this case from the second word of text line A yinganydyina. However, departing from the Central Australian style, at the end of the first melodic cycle, the performer takes a breath part of the way through the second word of text line A yingany- (see stave 4). Rather than omitting the end of this word-dyina while taking a breath and then commencing 
Melodic Cycle 2 with text line B mindi yarrabanydyina as typically occurs in the Central Australian style, the singer omits -dyina and then interrupts the text cycle: he jumps forwards to the first word of text line A of the text cycle wanydyalmirri, singing 'in his head' until the fourth syllable -rri. ${ }^{5}$

While not consistently applied in all nurlu song performances, Keogh suggests that this technique (jumping to the beginning of the text cycle at the beginning of a new melodic cycle) appears to be a significant feature of western Kimberley performance practice that distinguishes it from the Central Australian style (Keogh 1990: 207).

This is supported by my own analysis, which finds this technique used in the junba/balga genre, as practised by Worrorran language family groups to the northwest, and Bunuban and Jarrakan language family groups to the east and northeast. In a sample of approximately 500 distinct Worrorra, Ngarinyin, and Wunambal junbalbalga songs (Worrorran language family groups), containing both solo and group performances, all but three songs are regularly performed with the breaking technique observed by Keogh in the southwestern tradition of nurlu: in junba, the text cycle is recommenced at the beginning of each melodic cycle. The galinda song Jalaworarra (Willy Willy), ${ }^{6}$ composed by Worrorra composer Watty Ngerdu in the 1950s, and performed by Ngarinyin, Worrorra, and Wunambal peoples today, illustrates this. In the example set out in Figure 3, the text cycle of Jalaworarra is presented: jalaworarra rudngeyen jalawa jamimid rudnganja (text line A) / lalanggarra geyingerri beyinba geyingerri (text line B). In the performance represented in Figure 3 (led by elder singers Matthew Martin and Pansy Nulgit), following a complete iteration of the $\mathrm{AB}$ text cycle, a repeat is commenced. However, the text cycle is broken after the A line, and recommenced at the beginning of the next melodic cycle (AB). This recurs at the end of the second and third melodic cycles. In the fourth and final melodic cycle, the singers perform two complete iterations of the text cycle: ABAB. The 'breaking' of the text cycle in this way is common in junba, irrespective of whether the text cycle has an undoubled $(\mathrm{AB}$ or $\mathrm{ABC})$ structure or the more common doubled structure (AABB).

5 Note that Keogh begins a new stave at the beginning of each new melodic cycle, sometimes leaving a section of stave that has no notation. This has no durational value.

6 A willy willy is a whirlwind. 
Melodic cycle 1

A jalaworarra rudngeyen jalawa jamimid rudnganja $B$ lalanggarra geyingerri beyinba geyingerri

A jalaworarra rudngeyen jalawa jamimid rudnganja

Melodic cycle 2

A jalaworarra rudngeyen jalawa jamimid rudnganja B lalanggarra geyingerri beyinba geyingerri

A jalaworarra rudngeyen jalawa jamimid rudnganja

Melodic cycle 3

A jalaworarra rudngeyen jalawa jamimid rudnganja B lalanggarra geyingerri beyinba geyingerri A jalaworarra rudngeyen jalawa jamimid rudnganja

\section{Melodic cycle 4}

A jalaworarra rudngeyen jalawa jamimid rudnganja B lalanggarra geyingerri beyinba geyingerri A jalaworarra rudngeyen jalawa jamimid rudnganja B lalanggarra geyingerri beyinba geyingerri

Figure 3. Distribution of text and melodic cycles in Jalaworarra (Willy Willy)

Source: Composed by Watty Ngerdu (galinda junba), led by Matthew Martin and Pansy Nulgit, Mowanjum Festival, 10 July 2014

By contrast, in inma, purlapa, awely, and other song genres indigenous to the Central Australia and the Western Desert regions, the text cycle is uninterrupted: undoubled $A B$ text cycles, such as that in Figure 3, would be performed $A B A B A B A B$ and so on (rather than $A B A A B A A B A A B A B$, as in Ngerdu's Jalaworarra). Even when a breath is taken, contrasting Keogh's nurlu sample, the rest that accompanies the breath has the same duration as the omitted syllable (see, for example, Ellis 1964: 179). The repetition of the text cycle, as far as the performers are concerned, is uninterrupted (see also Tunstill 1987: 126; Turpin 2005: 124).

The treatment of the text cycle (uninterrupted versus interrupted) distinguishes Central Australian and Kimberley musical styles. These distinctive text cycle treatments correspond to distinctive principles of melodic organisation. Whereas in Central Australian genres the text cycle and melodic cycle are independent (each melodic cycle may begin from a different segment of text), in Kimberley genres there is a clear dependency (each melodic cycle commences with a new text cycle). These two modes of melodic/text setting are referred to as non-coterminous and coterminous, respectively (see Barwick 2011; Treloyn 2014). While nurlu demonstrates instances of both approaches, junbalbalga exhibits the coterminous approach in all but three of approximately 500 instances. Widening our view to genres from the Daly-Fitzmaurice (djanba, wangga, lirrga) and Arnhem land (kun-borrk, manikay), a continuum of musical style emerges that moves from cyclical/non-coterminous (Central Australia) to strophic/coterminous (northern Australia), transitioning in the Kimberley (see Figure 4). 


\begin{tabular}{|c|c|c|c|c|c|}
\hline Genre & $\begin{array}{l}\text { Cyclical } \\
\text { texts }\end{array}$ & $\begin{array}{l}\text { Non- } \\
\text { coterminous } \\
\text { texts }\end{array}$ & $\begin{array}{l}\text { Coterminous } \\
\text { texts }\end{array}$ & $\begin{array}{l}\text { Strophic } \\
\text { texts }\end{array}$ & Region \\
\hline $\begin{array}{l}\text { inma, purlapa, } \\
\text { yawulyu }\end{array}$ & $\checkmark$ & $\checkmark$ & $\mathrm{x}$ & $\mathrm{x}$ & $\begin{array}{l}\text { Central Australia, } \\
\text { Western Desert }\end{array}$ \\
\hline nurlu & $\checkmark$ & $\checkmark 2 / 3$ cases & $\checkmark 1 / 3$ cases & $x$ & Southwest Kimberley \\
\hline junba/balga & $\checkmark$ & $\checkmark 3 / 500$ & $\checkmark 497 / 500$ & $x$ & Northwest Kimberley \\
\hline djanba & $x$ & $\mathrm{x}$ & $\checkmark$ & $\checkmark$ & Daly-Fitzmaurice \\
\hline wangga, lirrga & $\mathrm{x}$ & $x$ & $\checkmark$ & $\checkmark$ & Daly-Fitzmaurice \\
\hline manikay & $\mathrm{x}$ & $\mathrm{x}$ & $\checkmark$ & $\checkmark$ & Arnhem Land \\
\hline
\end{tabular}

Figure 4. Distribution of text types in selected genres in Central Australia, the Kimberley, and North Australia

$\checkmark$ = present; $x=$ absent.

\section{The boundaries of musical style and analysis: The travelling warrior junba}

The comparison of musical style set out in this chapter makes a small contribution to our understanding of the musical landscape of Central Australia, northern Western Australia, and the Northern Territory. The scheme delineates similarities and distinctions between Kimberley, Central Australian, and Northern styles. But what are the implications of this analysis? To the extent that the continuum positions the Kimberley as a site of musical influences-received from both the south and the north-is there a tacit suggestion of stylistic 'cultural grey out' (Lomax 1968: 4), lending itself to a deficit view of the state of Aboriginal Australian traditions? Do we now have our hands on the lid of Mackinlay's colonial 'Pandora's box' (see Mackinlay 2012)?

Anthropologist Deborah Bird Rose came to understand boundaries (geographical, temporal, and personal) in the Victoria River District (to the east of the Kimberley) and bordering the Desert as productive zones in which relationships are affirmed:

Tracks and songs are the basis to Aboriginal maps and are often called 'boundaries'. To say that there are boundaries is to say that there are differences; the universe is not uniform. Unlike European maps on which boundaries are lines that divide, tracks connect points on the landscape, showing relationships between points. These are 'boundaries' that unite. The fact that a Dreaming demarcates differences along the line is important to creating variation, but ultimately a track, by its very existence, demarcates a coming together. Dreaming creativity made possible the relationships which connect by defining the differences that divide. (Rose 1992: 52) 
The analysis presented in this chapter might be seen to have taken the European approach described by Rose; the chapter has pursued differences between regional practice, mapping musical types as 'lines that divide'. In order to understand the 'relationships between points' and how musical difference 'demarcates a coming together', we must turn to the minutiae of performances, their cultural symbolism, and the role they play in enacting sociocultural processes.

As noted, all but three of approximately 500 Ngarinyin, Worrorra, and Wunambal junbalbalga songs exhibit coterminous text cycles that distinguish them from songs in the Central Australian style. The remaining three songs exhibit textual, rhythmic, and melodic features that are closely aligned with the Central Australian musical style. The relationship between the text cycle and melodic cycles in a performance of one of these songs, Jinbiri (Travelling Warrior), is set out in Figure 5. Contrasting Jalaworarra (Willy Willy; from the same repertory and composer; see Figure 3), the text cycle of Jinbiri (Travelling Warrior) exhibits distinctly Central Australian characteristics: the cyclical repetition of the undoubled text is uninterrupted throughout the song performance irrespective of melodic cycles (ABABABABAB and so on) and the song ends midway through the first word (Jin ...). ${ }^{7}$

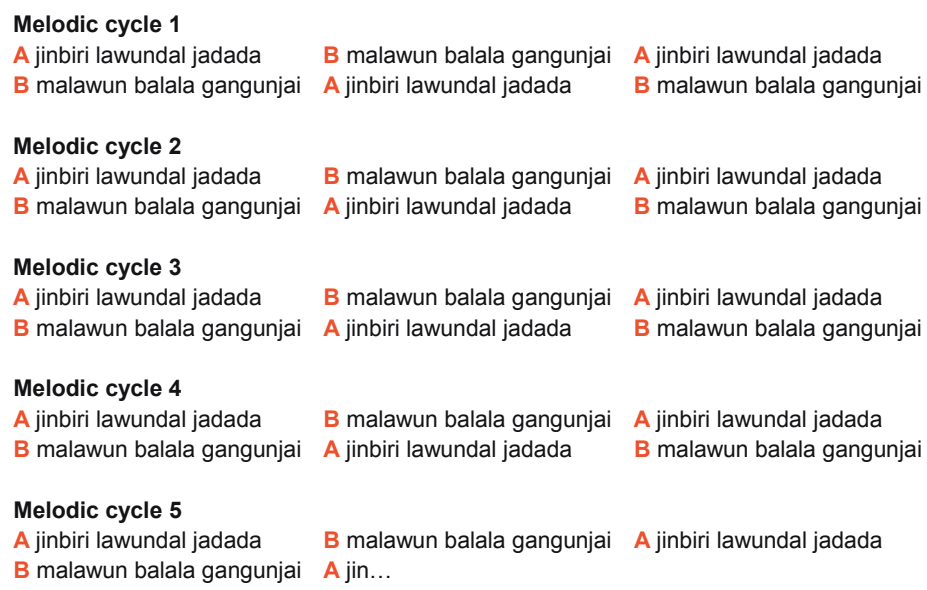

Figure 5. Distribution of text and melodic cycles in Jinbiri (Travelling Warrior)

Source: By Watty Ngerdu, led by Matthew Martin and Pansy Nulgit, Mowanjum Festival, 10 July 2014

7 Performances of this song by senior Ngarinyin songman Paddy Neowarra (deceased) consistently commence on lawundal, rather than first word of the text cycle (jinbiri), also reminiscent of the Central Australian style. 
In performances, this song is both preceded and followed by songs that exhibit the distinctly Kimberley style, as set out in Figure 6.

\begin{tabular}{|c|c|c|c|}
\hline \multicolumn{2}{|c|}{ Mowanjum Festival, 12 July 2012} & \multicolumn{2}{|c|}{ Mowanjum Festival, 10 July 2014} \\
\hline Song (Composer) & $\begin{array}{l}\text { Musical } \\
\text { Style }\end{array}$ & Song (Composer) & $\begin{array}{l}\text { Musical } \\
\text { Style }\end{array}$ \\
\hline Balara 'Canoe' (Woolagoodja) & Kimberley & Gurreiga 'Brolga' (Martin) & Kimberley \\
\hline Wurawun 'Warm Up' (Woolagoodja) & Kimberley & Mawala '?' (Wirrijangu) & Kimberley \\
\hline Gorrgorruma 'Fast walk' (Woolagoodja) & Kimberley & Gura ngonda 'Bush Doctor' (Martin) & Kimberley \\
\hline Wurawun 'Warm Up' (Woolagoodja) & Kimberley & Biyende 'Baby' (Martin) & Kimberley \\
\hline Gumarrangga 'Old Man' (Woolagoodja) & Kimberley & Lura 'Agula' (Ngerdu) & Kimberley \\
\hline Wurawun 'Warm Up' (Woolagoodja) & Kimberley & Biyu 'Rope' (Martin) & Kimberley \\
\hline Gumarrangga 'Old Man' (Woolagoodja) & Kimberley & Jinbiri 'Travelling Warrior' (Ngerdu) & $\begin{array}{l}\text { Central } \\
\text { Australian }\end{array}$ \\
\hline Wurawun 'Warm Up' (Woolagoodja) & Kimberley & Dudu 'Flying Doctor' (Ngerdu) & Kimberley \\
\hline Jadmila (Woolagoodja) & Kimberley & Winjagen 'Mt Agnes' (Martin) & Kimberley \\
\hline Wurawun 'Warm Up' (Woolagoodja) & Kimberley & Biyu 'Rope' (Martin) & Kimberley \\
\hline Jadmila '?' (Woolagoodja) & Kimberley & Manaliyan 'Mt House' (Ngerdu) & Kimberley \\
\hline Gubard 'Warm Up' (Ngerdu) & Kimberley & Wanalirri (Ngerdu) & Kimberley \\
\hline Lura 'Agula' (Ngerdu) & Kimberley & Gubard 'Warm Up' (Ngerdu) & Kimberley \\
\hline Gubard 'Warm Up’ (Ngerdu) & Kimberley & Ninbi 'Three Tribes' (Ngerdu) & Kimberley \\
\hline Jinbiri 'Travelling Warrior' (Ngerdu) & $\begin{array}{l}\text { Central } \\
\text { Australian }\end{array}$ & \multirow[t]{3}{*}{ — end of performance - } & \\
\hline Gura ngonda 'Bush Doctor' (Martin) & Kimberley & & \\
\hline Ninbi 'Three Tribes' (Ngerdu) & Kimberley & & \\
\hline
\end{tabular}

Figure 6. Junba songs and distribution of musical style in the Mowanjum Festival in 2012 and 2014

This deployment of musical styles exemplifies a technique of parataxis and juxtaposition that is seen at multiple levels of song and performance construction in both Central Australian and Northern Australian musical styles, wherein minimally varied musical and/or semantic content is performed to create an 'inductive space' (Barwick 2005a, 2005b; Treloyn 2007). As has been explored elsewhere, composers and performers use parataxis and juxtaposition to articulate personal and group identifications across culture and language (Sutton 1987; Barwick 1989; Turpin, R. Moyle, and Bonney in this volume). In the case of Ngarinyin junba, parataxis and juxtaposition are symbolic of a mode of creativity that is embedded in the ornodlamarlad moiety system (see Redmond 2001; Treloyn 2007).

Looking more closely at the symbolism embedded in the use and deployment of Central Australian style songs in junba, the cultural analyses of anthropologist Anthony Redmond provide valuable insights. Redmond has observed recurrent expressions that foreground 'difference against a background of similarity' (Redmond 2001: 136) when Ngarinyin people refer to 'Desert-side' peoples (i.e. groups from Walmajarri southwards). Redmond has discussed this as core to Kimberley-Desert 
relationship marking, in relation to both skin (where people note that Desert-side people have many skins, while Ngarinyin have only two (see Redmond 2001)), and in funeral ceremonies:

Some Ngarinyin people at Mowanjum, affines of the deceased man, applied red ochre to their bodies. They told me that this was the 'law' for the Walmajarri and other 'desert-side peoples', and that this was used in Mowanjum (the residents of which are mostly 'ranges people' from the north) only for the people who had marriage connections to those groups. Ngarinyin people regularly pointed to such contrasts with their southern desert neighbours, particularly in regard to the timing of the various phases of their own mortuary ceremonies. Many of them took opportunities that presented themselves to distinguish their own practices from those of 'desert-side' people ... These distinctions in temporal deployments in mortuary practices were particularly amplified when regional cultural identities were being contrasted. (Redmond 2008: 71)

This interpretation of the symbolism in the use of the Central Australian musical style is further supported by implicit references to the 'Desertside' in the song text of Jinbiri (Travelling Warrior), accompanying dance, and performance context (Figure 7).

Text line A

jinbiri lawundal jadada

Pansy Nulgit: He made a spear (jinbiri or gimbu with a rock tip), at the big place (lawunda), he chased (jada) them.

\section{Text line B}

malawun balala gangunjai

That open place (balala), I was going there.

Matthew Martin: Jinbiri lawundal - that's the traveller. He's the man with the spear. He used to walk, telling stories for that lawundal ... He was a teacher-traveller, a messenger. He used to tell people 'they got big junba down there', carrying a message stick like a letter.

He was spirit man, an anguma ... let different tribes know there's another junba coming up, big one, small one. He used to walk alone. Jinbi ... Traveling on his own, like a mailman ...

He was the mailman with the spear. He used to walk, telling story, for lawundul. That lawundul is all round. He travelled the land. He was travelling everywhere, learning, teaching, anything you know. He used to travel place to place, you know, telling what was happening place to place. He was the mailman, message carrier.

Figure 7. Text and glosses for Jinbiri (Travelling Warrior)

Source: Composed by Watty Ngerdu. Glosses by Pansy Nulgit and Matthew Martin

The text of Jinbiri (Travelling Warrior) describes a man who walked to distant countries and tribes, carrying a spear and messages, in this case an invitation to a junba event. In this context, the use of a Central Australian musical style may be symbolic of affirming relationships with distantDesert-side-groups. As the Travelling Warrior ventures to distant groups what is musically shared (cyclicity, isorhythm) and what is musically 
distinct (uninterrupted versus interrupted texts, for example) between Kimberley and Desert peoples is performed. The use of the Central Australian style marks a relationship with Desert-side peoples.

The dance that accompanies Jinbiri (Travelling Warrior) provides insight into how the use of this musical style is not just symbolic, but may serve to actively affirm relationships. The annual Mowanjum Festival has been a primary performance event for Ngarinyin, Worrorra, and Wunambal peoples since 1997, supported by the Mowanjum Art and Culture Centre. Ngarinyin, Worrorra, and Wunambal communities associated with Mowanjum use the festival to celebrate, teach, and learn about shared spiritual beliefs and to welcome 'strangers' (ngulmud or mawarra, in Ungarinyin), including more distant Kimberley, Desert-side, and northern Aboriginal groups and individuals, as well as non-Aboriginal groups and individuals from regional towns and tourists. The Jinbiri (Travelling Warrior) dance-song often features in the festival program (as illustrated in Figure 6). As pictured in Figure 8, the dance features a single male dancer (in this case Folau Penaia Umbagai) acting the Travelling Warrior, carrying a spear and spear-thrower. He dances across the dance ground, looking around, sometimes lunging towards the audience (the 'strangers') with spear-thrower and spear raised as if to launch it towards them to the delight of the audience.

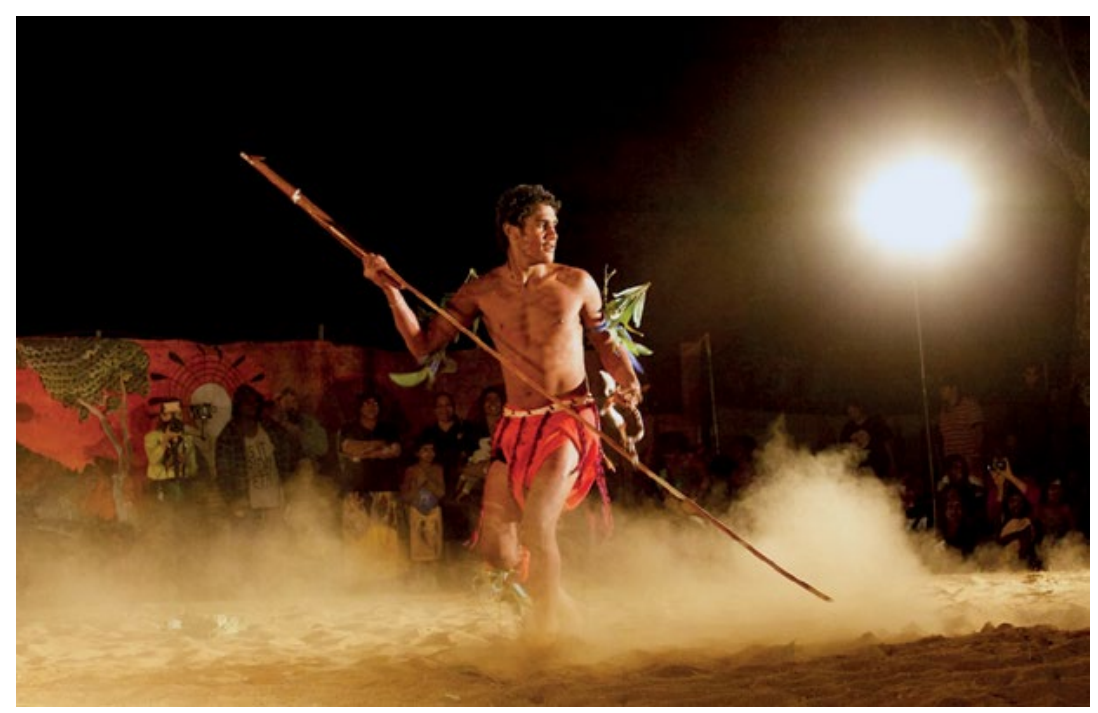

Figure 8. Folau Penaia Umbagai dancing Jinbiri (Travelling Warrior), Mowanjum Festival, 10 July 2014

Source: Matt Scurfield @ Mowanjum Art and Culture Centre, used with permission 
Rose notes that:

Boundaries are maintained by being pressed against. This is the meta-rule of response: to be is to act; to act is to communicate; to communicate is to test and to respond. The process of testing and responding affirms relationships. (Rose 1992: 223)

The Travelling Warrior dancer does not passively approach the boundary that separates himself and the strangers in the audience. Rather, he presses and tests the boundary. His posturing, lunging, withdrawal, and subsequent lunging serves to draw attention to what inhabits his world, and what inhabits that of the 'strangers'. His testing invites a response: attention to and engagement in his performance. Similarly, the traveller in the glosses provided by Martin in Figure 7 does not passively pass on his message, but rather invites a return action and response- a visit from the distant group.

It is not clear if the use of the Central Australian musical style for this song is directed at a particular cultural group, or is rather a relational gesture toward visitors and groups who have 'same but different' musical and cultural identities (see Barwick 2011; Treloyn 2014). However, the fact that the festival audience frequently includes Desert-side visitors, either family members of the local community or visiting performing groups, emphasises the sociocultural function of the use of the Central Australian musical style in the festival to affirm relationships.

For the outsider, comparative musical analysis maps a regional perspective of the musical language of the region. The symbolic and sociocultural context in which the language is sung and danced provides insight into the way in which performers utilise musical language as a sociocultural tool to represent, manage, and operationalise relationships in the past and present.

\section{Conclusion}

The Travelling Warrior ventures into strange territories to transmit a message, an invitation. Spear and spear-thrower in hand, he tests the boundaries of the dance ground, and of social and cultural groups. For Rose, in Yarralin society to the east: 
principles of symmetry and response ensures that as any part tests the limits of its context by pressing others, it is balanced by a return pressure. Boundaries are preserved through pressure, with the ultimate aim that nothing happen.

That the process of testing has the potential to generate hostilities is a fact of life. (Rose 1992: 223)

This chapter has been concerned with boundaries: the boundaries of the Travelling Warrior on the dance ground at the Mowanjum Festival; boundaries between Central Australian, Kimberley, and Northern Australian musical styles; boundaries between European and Aboriginal Australian epistemologies of musical experience; and, after Wild, boundaries between the ethnomusicologies of Australia and elsewhere.

The pressing of boundaries may be dangerous as Rose suggests. The Travelling Warrior, with his spear-thrower and spear, is prepared. Singers, with mastery of Kimberley and Central Australian musical styles, are prepared. And, hopefully, ethnomusicologists conducting comparative analysis attentive to sociocultural and historical contexts are also prepared. The colonialist connotations of comparative analysis in Australian ethnomusicology, in hand with its tendency towards abstraction and complexity, may rightly generate hostilities. Testing boundaries, as Rose notes, 'is a fact of life'. It is a fact of intercultural ethnomusicology in the Australian context and, accordingly, we may well be afraid to pursue theoretical schema of Aboriginal Australian musical styles, as Wild wondered. We press this boundary, however, with political consciousness and respond with attention to the musical, historical, and sociocultural particulars of performances and intercultural research; listening for the distinctive voices of Aboriginal composers, singers, movements, and styles, past and present, and for our own.

\section{Acknowledgements}

The research presented in this chapter was supported by the Mowanjum Art and Culture Centre and Australian Research Council Linkage Project 'Strategies for preserving and sustaining Australian Aboriginal song and dance in the modern world: The Mowanjum and Fitzroy River valley communities of WA' (LP0990650). Special thanks are due to Matthew 
Dembal Martin and Pansy Nulgit for sharing explanations of the song Jinbiri (Travelling Warrior), Rona Googninda Charles for assisting with permissions, and Myfany Turpin for reading and commenting on a version of this chapter.

\section{References cited}

Barwick, Linda. 1989. 'Creative (Ir)regularities: The Intermeshing of Text and Melody in Performance of Central Australian Song.' Australian Aboriginal Studies 1989 (1): 12-28.

- 2005a. 'Performance, Aesthetics, Experience: Thoughts on Yawulyu Mungamunga Songs.' In Aesthetics and Experience in Music Performance, edited by Elizabeth Mackinlay, Denis Collins, and Samantha Owens, 1-18. Newcastle: Cambridge Scholars Press.

—_. 2005b. 'Marri Ngarr Lirrga Songs: A Musicological Analysis of Song Pairs in Performance.' Musicology Australia 28 (1): 1-25. doi.org /10.1080/08145857.2005.10415276.

—. 2011. 'Musical Form and Style in Murriny Patha Djanba Songs at Wadeye (Northern Territory, Australia).' In Analytical and CrossCultural Studies in World Music, edited by Michael Tenzer and John Roeder, 303-42. New York: Oxford University Press.

Bowern, Claire, and Harold Koch. 2004. ed. Australian Languages: Classification and the Comparative Method. Amsterdam: John Benjamins Publishing.

Ellis, Catherine. 1964. Aboriginal Music Making: A Study of Central Australian Music. Adelaide: Libraries Board of South Australia.

- 1985. Aboriginal Music, Education for Living: Cross-Cultural Experiences from South Australia. St Lucia: University of Queensland Press.

Furlan, Alberto. 2008. 'Indigenous Songs as "Operational Structures of Transactional Life": A Study of Song Genres at Wadeye.' In An Appreciation of Difference: W. E. H. Stanner and Aboriginal Australia, edited by Melinda Hinkson and Jeremy Beckett, 151-68. Canberra: Aboriginal Studies Press. 
Keogh, Raymond. 1990. 'Nurlu Songs of the West Kimberleys.' PhD diss., University of Sydney.

Knopoff, Steven. 1992. 'Yuta Manikay: Juxtaposition of Ancestral and Contemporary Elements in the Performance of Yolngu Clan Songs.' Yearbook of the International Council for Traditional Music 24: 138-53. doi.org/10.2307/768475.

- _. 2003. 'What Is Music Analysis? Problems and Prospects for Understanding Aboriginal Songs and Performance.' Australian Aboriginal Studies 2003 (1): 39-49.

Lomax, Alan. 1968. Folk Song Style and Culture. Washington, DC: American Association for the Advancement of Science.

Mackinlay, Elizabeth. 2012. 'Decolonising Australian Ethnomusicology through Autoethnography.' Creative Approaches to Research 5 (1):3-14.

Magowan, Fiona. 2007. Melodies of Mourning: Music and Emotion in Northern Australia. Oxford: James Currey; Crawley: University of Western Australia Press.

Marett, Allan. 2005. Songs, Dreamings, Ghosts: The Wangga of North Australia. Middletown, CT: Wesleyan University Press.

Marett, Allan, Martin Anggalitji Warrigal, and Robert Ilyerre Daly. 1991. 'Wangga Songs of Northwest Australia: Reflections on the Performance of Aboriginal Music at the Symposium of the International Musicological Society '88.' Musicology Australia 14: 37-46.

Moyle, Alice. 1966. A Handlist of Field Collections of Recorded Music in Australia and Torres Strait. Canberra: Australian Institute of Aboriginal Studies.

—_. 1974. 'North Australian Music: A Taxonomic Approach to the Study of Aboriginal Song Performances.' PhD diss., Monash University.

- 1977. Aboriginal Sound Instruments. Companion booklet for a 12-inch LP disc. AIAS/14. Canberra: Australian Institute of Aboriginal Studies.

Redmond, Anthony. 2001. 'Rulug Wayirri: Moving Kin and Country in the Northern Kimberley.' PhD diss., University of Sydney. 
. 2008. 'Time Wounds: Death, Grieving and Grievance in the Northern Kimberley.' In Mortality, Mourning and Mortuary Practices in Indigenous Australia, edited by Katie Glaskin, Myrna Tonkinson, Yasmine Musharbash, and Victoria Burbank, 69-86. Farnham, UK: Ashgate.

Rose, Deborah Bird. 1992. Dingo Makes Us Human: Life and Land in an Australian Aboriginal Culture. Cambridge: Cambridge University Press.

Savage, Patrick, and Steve Brown. 2013. 'Toward a New Comparative Musicology.' Analytical Approaches to World Music 2: 148-98.

Stanner, W. E. H. 1966. On Aboriginal Religion, Oceania Monograph, 11. Sydney: University of Sydney.

Sutton, Peter. 1987. 'Mystery and Change.' In Songs of Aboriginal Australia, edited by Margaret Clunies Ross, Tamsin Donaldson, and Stephen A. Wild, 77-96. Oceania Monograph, 32. Sydney: University of Sydney.

Toner, P. G. 2007. 'The Gestation of Cross-Cultural Music Research.' In 'Historicizing Cross-cultural Research', edited by Benjamin Penny, special issue, Humanities Research 14 (1): 85-110. Accessed 31 January 2015. press.anu.edu.au/hrj/2007_01/mobile_devices/index.html.

Treloyn, Sally. 2006. 'Songs that Pull: Composition/performance through Musical Analysis.' Context: A Journal of Music Research 31: 151-64.

- 2007. 'Flesh with Country: Juxtaposition and Minimal Contrast in the Construction and Melodic Treatment of Jadmi Song Texts.' Australian Aboriginal Studies 2007 (2): 90-99.

—. 2014. 'Cross and Square: Variegation in the Transmission of Songs and Musical Styles between the Kimberley and Daly Regions of Northern Australia.' In Circulating Cultures: Exchanges of Australian Indigenous Music, Dance and Media, edited by Amanda Harris, 203-38. Canberra: ANU Press.

- 2016. 'Music in Culture, Music as Culture, Music Interculturally: Reflections on the Development and Challenges of Ethnomusicological Research in Australia.' Voices: A World Forum for Music Therapy 16 (2). Accessed 24 December 2016. www.voices.no/index.php/voices/ article/view/877/724. 
Treloyn, Sally, Andrew Dowding, and Mary Anne Jebb. 2015. 'Tabi Tools for Change: Approaching the Solo Public Songs of the West Pilbara.' In The Music of Endangered Languages, FEL XIX - NOLA: Proceedings of the 19th Foundation for Endangered Languages Conference, edited by Nicholas Ostler and Brenda W. Lintinger, 45-51. Hungerford, UK: Foundation for Endangered Languages.

Tunstill, Guy. 1987. 'Melody and Rhythmic Structure in Pitjantjatjara Song.' In Songs of Aboriginal Australia, edited by Margaret Clunies Ross, Tamsin Donalson, and Stephen A. Wild, 121-41. Oceania Monograph, 32. Sydney: University of Sydney.

Turpin, Myfany. 2005. 'Form and Meaning of Akwelye: A Kaytetye Women's Song Series from Central Australia.' PhD diss., University of Sydney.

Wild, Stephen A. 2006. 'Ethnomusicology Down Under: A Distinctive Voice in the Antipodes?' Ethnomusicology 50 (2): 345-52. 
This text is taken from A Distinctive Voice in the Antipodes: Essays in Honour of Stephen A. Wild, edited by Kirsty Gillespie, Sally Treloyn and Don Niles, published 2017 by ANU Press, The Australian National University,

Canberra, Australia.

dx.doi.org/10.22459/DVA.07.2017.05 